\title{
Planning Industrial Location: A Fuzzy Model for Preventing Disastrous Overconcentration of Industries
}

\author{
Carlos A. N. Cosenza ${ }^{1 *}$, Ademir Clemente ${ }^{2}$, Luis Moura ${ }^{3}$ \\ COPPE-UFRJ, Academic Visitor, Department of Land Economy, 2017, University of Cambridge, UK. \\ Department of Accounting Sciences - Federal University of Paraná \\ DSc COPPE-UFRJ, LabFuzzy Researcher.
}

*Corresponding Author: Carlos A. N. Cosenza, COPPE-UFRJ, Academic Visitor, Department of Land Economy, 2017, University of Cambridge, UK

\begin{abstract}
This article aims to present a planning instrument to avoid the overconcentration of industrial plants and the bad effects it causes to the Environment and Human Health. To make clear the need for such an instrument, the ideas popularized by the World Bank at the end of the last century are confronted with the recent experience of the city of Cubatão in the State of São Paulo, although several other cities have similar stories, whether in Brazil or in other countries. The proposed model is based on the original approach by the Società per la Matematica e l'Economia Applicate and results from a research work at Martin Centre, Cambridge University, UK, 1981, and another at the Department of Land Economy, Cambridge University, UK, 2017.The need to increase GDP and create jobs, and the lack of technical information on the effects of industrial concentration in space frequently lead authorities to not consider the minimum quality levels of water, air and soil and neglect the standards set by the World Health Organization. The model consists of confronting demand profiles of industrial projects with supply profiles presented by locational alternatives, with compliance with WHO standards as a sine qua non condition. To make easier the application of the instrument, Fuzzy Logic and linguistic variables are employed.
\end{abstract}

Keywords: Industrial Planning; Industrial Location; Environment; World Health Organization; Applied Fuzzy Logic

\section{INTRODUCTION}

In 2012, Leo Hickman said about the 2012United Nations Climate Change Conference (COP18): "Export of pollution from rich countries moves Climate Conference" (HICKMAN, The Guardian, 2012). The Conference resumed the ideas popularized by the World Bank at the end of the last century about the export of pollution to poor and developing countries (MIRANDA, 2012).In fact, those ideas of pollution transfer to poor and developing countries resurfaced (WORLD BANK, 1991).According to such ideas, export of pollution should be an international policy.

On the other hand, authorities and planners in the least developed countries tend to see the implantation of industries as a sort of panacea, as capable to promote and accelerate economic development, by creating job opportunities and wealth. This has favored the implantation of pollutant industries in peripheral economies and, as a result, has made the proposed pollution transfer strategy a reality.

The World Health Organization (WHO) strictly established the maximum permissible levels of pollution. According to WHO, about $92 \%$ of the world's population live in places that do not meet minimum air quality conditions, resulting in thousands of deaths (BBC, 2016).The major concern of WHO is the frequent disruption of those standards as authorities tend to adopt instead local or regional standards. The local or regional standards are established to meet the interests of incentive policies whose economic justifications are questionable.

From the WHO's point of view, urgent government action is necessary to mitigate no communicable diseases:

Urgent government action is needed to meet global targets to reduce the burden of no communicable diseases (NCDs), and prevent the annual toll of 16 million people dying 
prematurely - before the age of 70 - from heart and lung diseases, stroke, cancer and diabetes[...]. [WHO, 2015].

Increasing pollution in already polluted areas can undoubtedly bring negative net benefits to the extent that the social cost of the diseases can outweigh the income and employment gains. Planners and authorities need to count on a comprehensive location model including economic, technical and environmental conditions to properly avoid locations that raise pollution above desirable standards.

Despite the seriousness of the issue, few studies attempt to embrace the full set of environmental impacts. Generally, they consider air, water and soil pollution separately. However, one should consider the confluence of those impacts and its harmful results on the population's health and the environment in making socio-environmental decisions.

The main objective of this article is to present an instrument of planning and assessment that makes possible to choose the better industrial location restricted to WHO's standards in respect to the air, water and soil.

The need to impose limits to entry of new pollutant units requires that national and international development agencies count on special algorithms. In stablishing those limits one should consider all the relevant attributes, dimensioning their participation in the positive and / or detrimental consequences to the economy, the environment and the human being.

National and international development agencies are conscious about the correlation between pollution and diseases, and the cumulative long-term effects. This has been the subject of many research works. In view of this, those agencies have to count on an instrument suitable for appraisal analysis including all sort of benefits and also all sort of costs, not only the increment to employment and Gross National Product (GNP). A number of experiences around the World make clear that when the WHO's standards are largely exceeded due to concentration of pollutant activities the increase in Public Health expenditures are likely to outweigh the increase in GDP.

In addition to this introduction, this article presents8 other sections: 2. Dirty Industry and the Least Developed Countries;3. Cubatão, an Example of Disastrous Industrial Overconcentration; 4. Interrelated Environmental Impacts of Industry; 5. Water and Groundwater Pollution; 6. Air Pollution and Air Quality; 7. Ground Contamination; 8. The Proposed Model; and 9.Final Considerations.

\section{DIRTY INDUSTRY AND THE LEAST DEVELOPED COUNTRIES}

Since the mid-1970s the not-in-my-back-yard (NIMBY) syndrome became popular in developed countries. The authorities and the population of developed countries became aware of the undesirability of having energy plants, especially nuclear, and industrial plants nearby them.

At the international level, the NIMBY syndrome was the predominant thinking in the World Bank. Lawrence Summers, the former chief economist of the World Bank (1991-3), based on orthodox economic reasoning, has stated the following about the pollutant industries:

'Dirty' Industries: Just between you and me, shouldn't the World Bank be encouraging more migration of the dirty industries to the LDCs [Least Developed Countries]? I can think of three reasons:

- The measurements of the costs of health impairing pollution depend on the foregone earnings from increased morbidity and mortality [...] a given amount of health impairing pollution should be done in the country with the lowest cost, which will be the country with the lowest wages [...].

- The costs of pollution are likely to be non-linear as the initial increments of pollution probably have very low cost $[\ldots]$.

- The demand for a clean environmental for aesthetic and health reasons is likely to have very high income elasticity. The concern over an agent that causes [...] prostate cancer is obviously going to be much higher in a country where people survive to get prostate cancer [...]. Also, much of the concern over industrial atmosphere discharge [...] These discharges may have very little direct health impact. [...] While production is mobile the consumption of pretty air is a non-tradable. [World Bank - Memo, 1991.]

According to this, the World Bank should incentive and finance the migration of pollutant industries to least developed countries. This way, humanity would achieve an overall reduction of costs and, as a consequence, an increase in the worldwide level of wellbeing. 
Certainly, the issue is much more complex.

It is well known that overconcentration of pollutant industries causes a wide range of noncommunicable diseases, including Parkinson's and Alzheimer's diseases. The heart and cardiovascular systems are highly vulnerable to numerous environmental agents including air pollution and metals such as arsenic, cadmium, and lead (COSSELMAN et al., 2015).

To make things worse, in least developed countries environmental authorities do not reach effectiveness in protecting the environment and the public health systems are weak or practically inexistent. Such systems are mostly overcharged and already are not able to take care of the population's health.

\section{CUbatão, An Example OF DiSASTROUS INDUSTRIAl OVER CONCENTRATION}

The city of Cubatão, located in Baixada Santista, on the coast of the state of São Paulo, underwent a rapid and ungoverned process of industrial concentration and became known worldwide due to the consequences on its population. In the 1980s, dozens of anencephalic children were recorded and the city does not present acceptable air quality yet. Air quality in the industrial area is considered very poor and far exceed the limits set by the WHO due to unfavourable conditions to the dispersion of air pollutants, as it is located in a valley.

Figure1. Presents the prevailing winds in Cubatão and their consequences

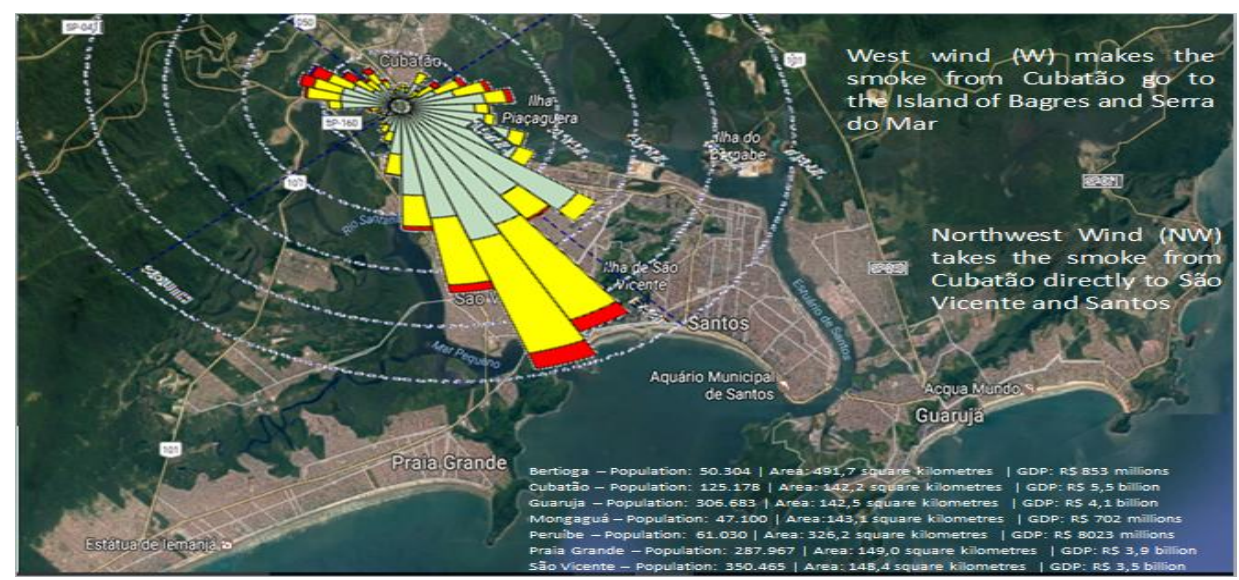

Figure1. Cubatão prevailing winds and areas affected by air contamination

Source: based on data from CETESB.

In the past, Cubatão has presented 69 micrograms of particulate matter (MP10) per cubic meter, when WHO recommends a maximum of 20 micrograms; and also 31 micrograms to fine particles (MP2.5) per cubic meter when the upper limit is 10 micrograms

Cubatão, sometimes referred to as The Death Valley, only received public actions after its situation acquired calamitous dimensions. In the early 1980s, the daily discharge of pollutants released in Cubatão was about 1,300 tons. These particles were deposited in the soil, rivers and mangroves. As a result, high infant mortality rates and neonatal deaths due to anencephaly announced a huge catastrophe. Soon, half of its residents presented respiratory diseases.

The topography of Cubatão is unfavourable to the dispersion of pollutants. Even worse, the predominant wind carries the pollution to Santos, the main city on the coast of São Paulo. Other badly polluted cities as Vapi (India), Norilsk (Russia) and Tianjin (China) present more open topography and the regular winds carry pollution to great distances.

Considered as the most polluted city in the world by the United Nations in the 1980's, Cubatão has gradually been improving over the years. As early as 1990, progressive recovery was set as an example for other communities affected by similar evils. However this requires heavy social investments and financial resources are scarce, which imposes slowness to the execution of needed services. Even in 2015 the air quality in the industrial area was classified as bad and very bad. Particulate matter indexes (MP10) recorded 40 micrograms per cubic meter, and in May of that year recorded 60 micrograms per cubic meter (PEDROSO, 2016). 
The drama of Cubatão is far from a happy end. The resilience of the environment has been disregarded and, as a consequence, recovery can take a long time. Sanitary landfills and all sort of industrial wastes are being cause of serious damages to the region's groundwater. Cubatão still presents an abnormal incidence of cancer and deaths, and toxic substances have been found even in breast milk. The aquifers also suffer contamination of the water supply stations by migration of waters located in their proximities. The damages relate to each other and result in a cumulative risk.

In Cubatão, aluminium sulphate is produced by 46 chemical plants. In 2017, part of Cubatão Industrial Complex had to be evacuated as a result of gas leak from a chemical company. Around 70 people were hit immediately on the spot, and acid rain was produced. Materials collected in mangrove swamps nearby Cubatão present high content of heavy metals such as cadmium, copper, lead and mercury.

Cubatão proves that the infrastructure of industrial poles built with public resources, including transport, communication and energy, generates a strong attraction. In a short time, this leads to surpassing permissible limits. Meanwhile, 3 the infrastructure for the treatment of waste and pollutants emitted is non-existent from the outset or rapidly presents insufficiency (SOARES,2013).

\section{INTERRELATED ENVIRONMENTAL IMPACTS OF INDUSTRY}

The three sets of effects of industrial activity into the environment are related to the quality of water, soil and air. One may analyse these effects through IF-THEN rules, considering the consequences of inhalation, ingestion and exposure to toxic materials. Figure 2 shows an example of matrix of consequences of emission of pollutants.

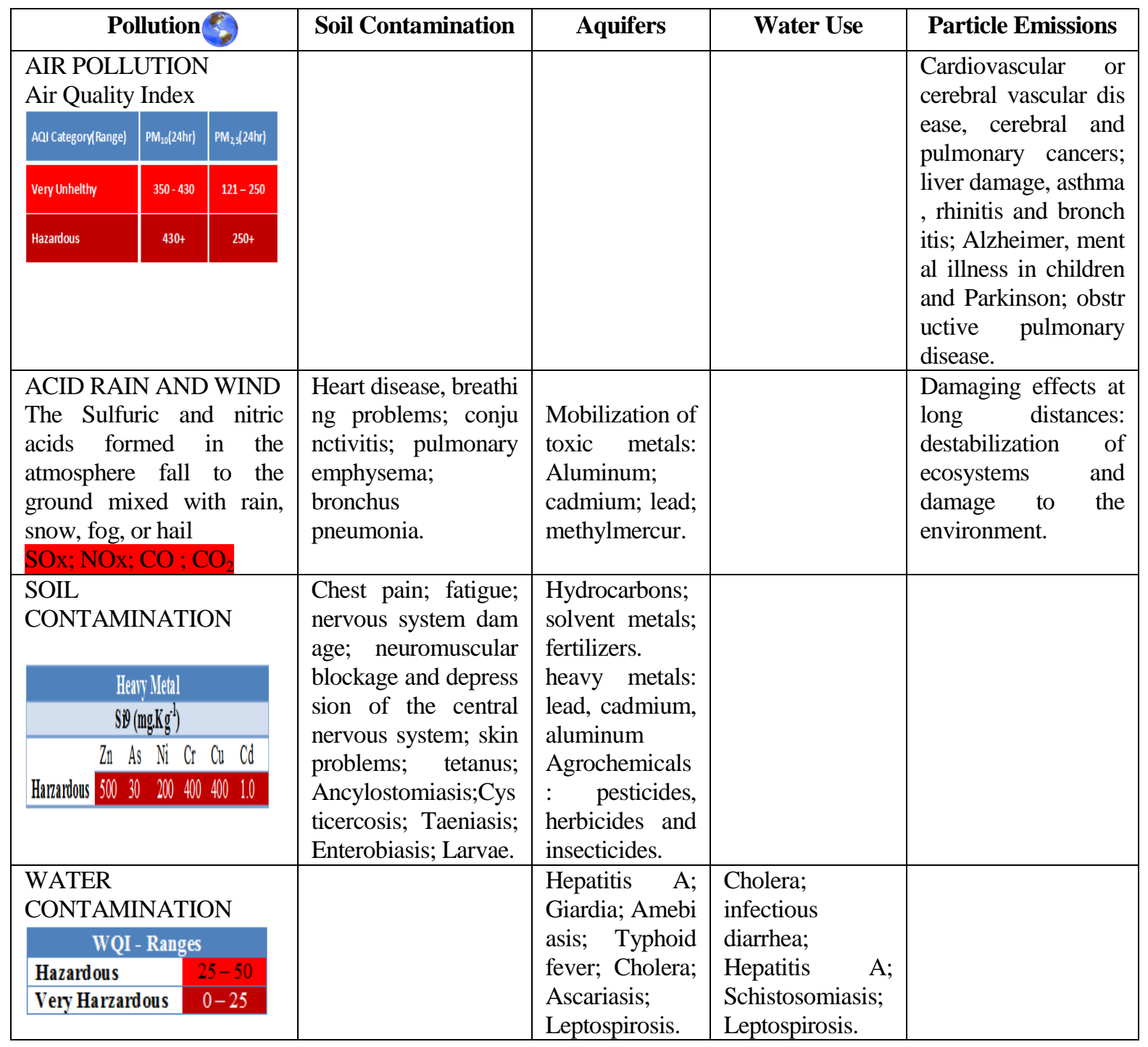

Figure2. Pollution and environment relations (an example)

Source: Based on BRIGGS, 2003. 
Most environmental damages caused to water, air, and soil quality are interrelated. Acid rain, caused by air pollution, for example, damages both aquatic and terrestrial ecosystem. Figure 3displays those interrelations.

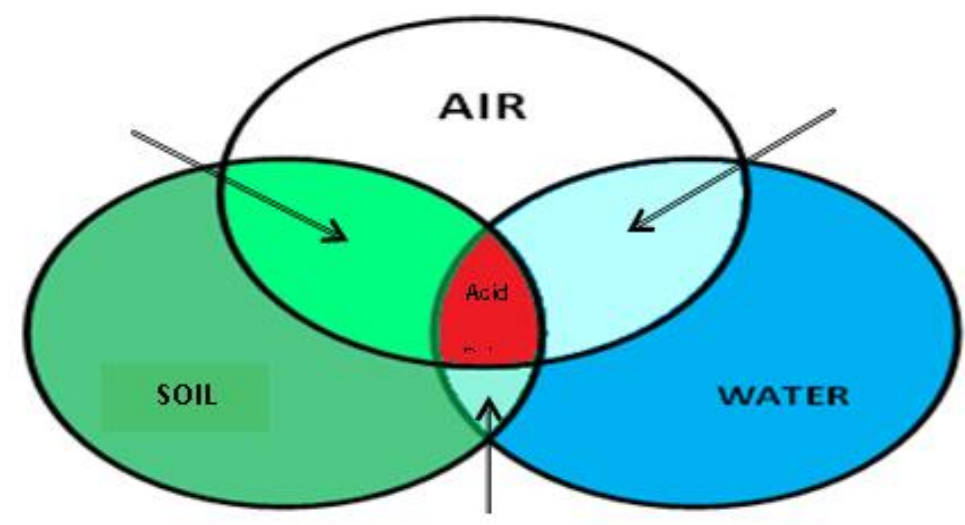

Figure3. Interrelations between environmental damages

Source: Adapted from NATHANSON and SCHNEIDER, 2016.

The cumulative risk assessment, as stated by CRAWFORD-BROWN and CRAWFORD-BROWN (2012), seeks to provide:

[...] a framework for systematically assessing the relative contributions of risk agents to the overall risk [...]. The intent is 1) to better characterize risks of mixtures, 2) to identify populations that may be more sensitive and susceptible to environmental exposures due to preconditions (such as exposure through other routes), and 3) to most effectively allocate resources for protection of public health.

In fact, the implant of a given industrial project may represent a prohibitive increase in emission of pollutants to the air, contamination of aquifers and surface water,surpassing the WHO's standards and causing environmental and health tragedies. In this case, planners and governmental authorities should deny the intended location and indicate other possible locations to the entrepreneur.

Henri Poincaré (1995) stated that "scientists work with analogies and analysts with elements of conviction". Knowledge leads to responsible actions. Generally, project analysis and approval is carried out without awareness of its consequences outside and far beyond the immediate economic scope.The lack of technical knowledge of the effects that a new industrial unit will cause to the environment and the health of the population brings certain tranquillity to those responsible as the analyses do not extend to such effects.

The project analyst knows that there is a relationship between scale, technology, and the production function. This allows calculating the scale reductions of the inputs but not the quantities of particles emitted by different quantities of inputs. As a consequence, the effects on water, air and soil are not accordingly anticipated. A derived production function can relate pollutant quantities to input quantities and, a step further, allows to estimate the effects on the environment and the population.

\section{WATER AND GroundWater Pollution}

Industrial chemical wastes disposed on the surface represent a dangerous source of groundwater contamination. As NATHANSON and SCHNEIDER (2016) state:

Many industrial impoundments of contaminated liquids leaked out of these landfills and lagoons, percolated through the soil, and reached a groundwater aquifer. [...] The recharge area for an aquifer is where precipitation infiltrates the ground to replenish the water flowing through the aquifer. This is an important factor in land-use planning and urban development.

Since 1965 a number of water quality indexes (WQI) has been developed. A variety of situations have led researchers to make relevant modifications and introduce new elements in their composition. A WQI provides a single number that expresses overall water quality at a certain location and time, based on several parameters. Those parameters may originate from consultation to specialized people using the Delphi Method. 
The WQI from National Sanitation Foundation (NSF) was created in 1970 and is based on nine parameters with respective weights (w) that are fixed according to their importance to the overall water quality. These parameters are:

- Dissolved oxygen (DO)

- Fecal coliform

- Potential of hydrogen $(\mathrm{pH})$

- Biochemical oxygen demand (BOD) (5-day)

- Temperature change (from 1 mile upstream)

- Total phosphate

- Nitrate

- Turbidity

- Total solids

The WQI classification is shown in Table 1

Table1. Water Quality Index Ranges

\begin{tabular}{|l|l|}
\hline \multicolumn{1}{|c|}{ Quality } & \multicolumn{1}{c|}{ Ranges } \\
\hline Excellent & $0-25$ \\
\hline Good & $25-50$ \\
\hline Medium & $50-70$ \\
\hline Hazardous & $70-90$ \\
\hline Very Hazardous & $90-100$ \\
\hline
\end{tabular}

Source: BROWN et al., 1970.

A fuzzy representation of the WQI classification is shown in Figure 4.

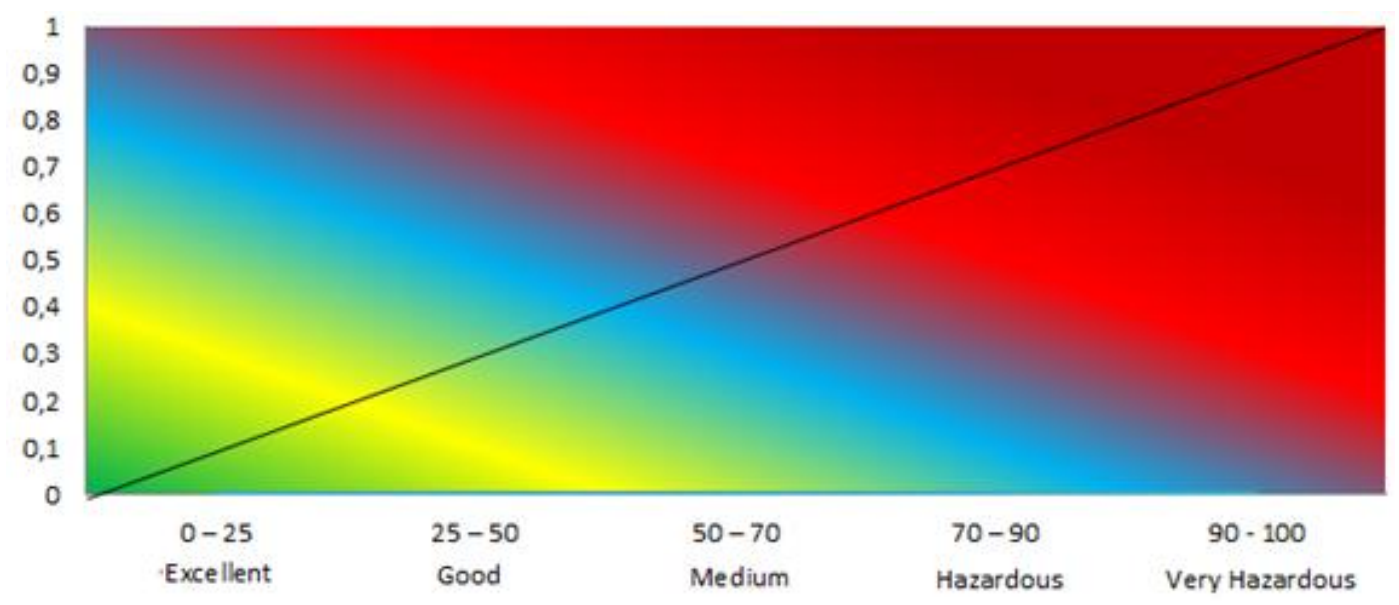

Figure4. Fuzzy representation of the water quality

Source: authors, 2018.

The Drastic Index, proposed by the Environmental Protection Agency (EPA), is specific for groundwater vulnerability measurement, and ranges from 1 to 5 , with 1 being the least vulnerable level. DRASTIC is taken from the initial letters of the seven parameters used:

- Dr, ratings to the depth to water table;

- $\mathrm{Rr}$, ratings for ranges of aquifer recharge;

- Ar, ratings assigned to aquifer media;

- $\mathrm{Sr}$, ratings for the soil media;

- $\operatorname{Tr}$, ratings for topography (slope); 
- $\quad \mathrm{Ir}=$ ratings assigned to vadose zone;

- $\mathrm{Cr}=$ ratings for rates of hydraulic conductivity.

Determination of the DRASTIC Index number is done by multiplying each parameter rating by its weight and adding together.

$$
I N D E X=D_{r} D_{w}+R_{r} R_{w}+A_{r} A_{w}+S_{r} S_{w}+T_{r} T_{w}+I_{r} I_{w}+C_{r} C_{w}
$$

Where the subscripts $\boldsymbol{r}$ and $\boldsymbol{w}$ refer to ratings and weights, respectively [RAMARAJU and VENI, 2017]. Recent formulations using fuzzy hierarchy combined with the DRASTIC model present greater amplitude because they consider more accurately the qualitative differences between the factors involved.

A meaningful association between groundwater vulnerability and hazard level is shown in Table 2.

Table2. Groundwater vulnerability and hazard level

\begin{tabular}{|l|l|}
\hline \multicolumn{1}{|c|}{ Vulnerability Level } & \multicolumn{1}{c|}{ Hazard Level } \\
\hline Low & Low \\
\hline Moderate & Medium \\
\hline Moderately high & High \\
\hline High & Very High \\
\hline
\end{tabular}

Source: Authors, 2018.

Table 3 presents the Demand and Supply Matrices to illustrate the application of four factors related to groundwater hazard level in deciding on a new industrial location.

Table3. Groundwater vulnerability and risk mapping

\begin{tabular}{|c|c|c|c|c|c|}
\hline \multicolumn{4}{|c|}{ Demand Matrix } & & \\
\hline \multicolumn{2}{|c|}{ Parameters / Attributes } & Toxicity & Mobility & Degradability & Amount / Volume \\
\hline \multicolumn{2}{|l|}{ Index } & $f_{1}$ & $f_{2}$ & $f_{3}$ & $f_{4}$ \\
\hline \multicolumn{2}{|c|}{$\begin{array}{l}\text { Source Index (hazard offered by potential } \\
\text { sources) }\end{array}$} & 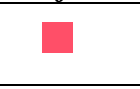 & घ & घ & - \\
\hline \multicolumn{6}{|c|}{ Weights } \\
\hline $\begin{array}{r}\quad=\text { Critical } \\
=\text { Conditional }\end{array}$ & & \multicolumn{4}{|c|}{$\begin{array}{l}=\text { Not very conditional } \\
=\text { Irrelevant }\end{array}$} \\
\hline
\end{tabular}

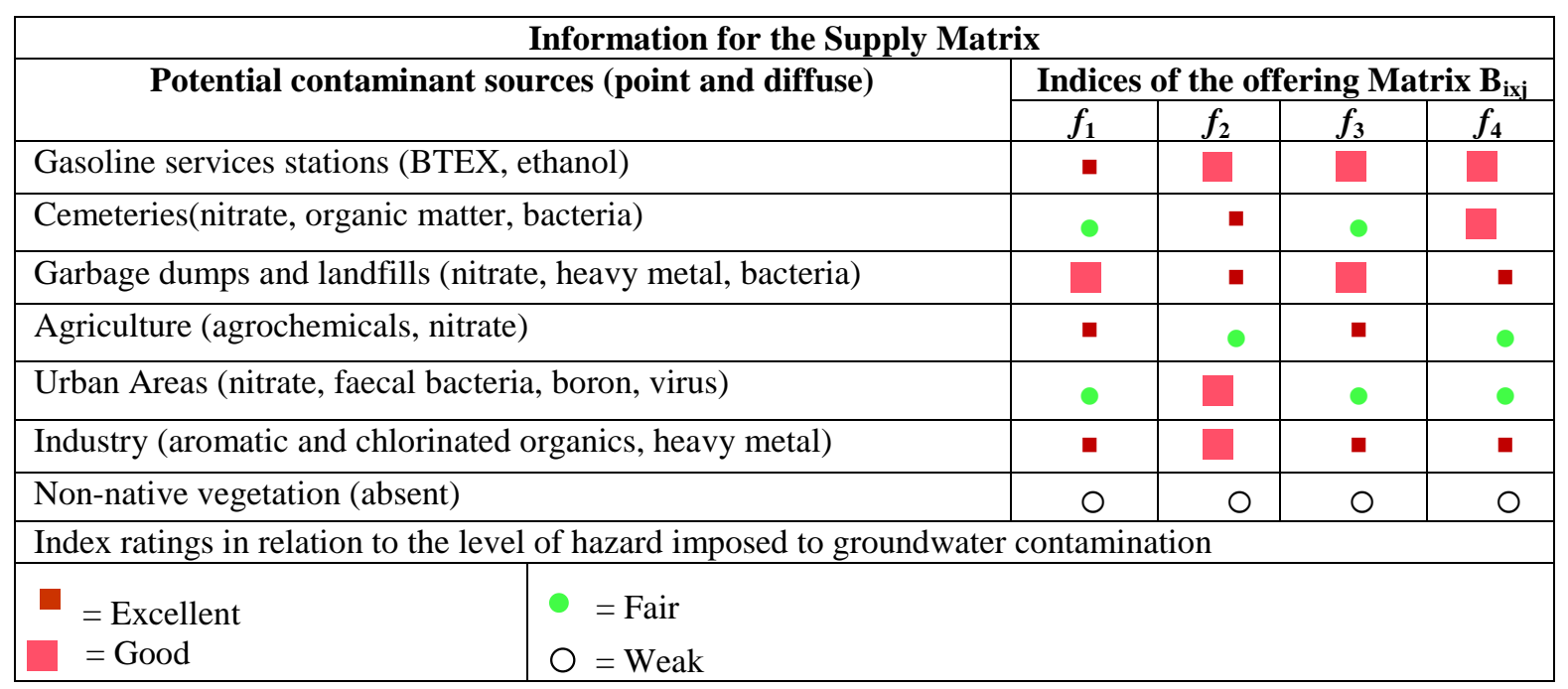

\begin{tabular}{|l|c|c|}
\hline \multicolumn{3}{|c|}{ Source Index Classification } \\
\hline \multicolumn{1}{|c|}{ Classification of sources } & Range & Index (SI) \\
\hline Low hazard level & $0-0,4$ & 1 \\
\hline Medium hazard level & $0,4-0,07$ & 4 \\
\hline High hazard level & $0,7-1,0$ & 7 \\
\hline Very high hazard level & $>1,0$ & 10 \\
\hline
\end{tabular}

Source: NOBRE et al., 2007.

International Journal of Managerial Studies and Research (IJMSR) Page |44 
The Aquifer Vulnerability Index (AVI) is based on two key parameters:

- Thickness of each sedimentary unit above the uppermost aquifer; and

- Estimated hydraulic conductivity of each of these layers.

According to Dale Van Stempvoort et al., (1993), "Using water well records, these parameters are combined to obtain a reasonable estimate of the hydraulic resistance of the protective aquitard cover if present, at each site.[...] AVI maps can be used to help define groundwater protection zones, or for screening sites for land use selection".

\section{Air Pollution ANd Air Quality}

The air quality index (AQI) is based on five criteria measured on a scale from 0 to 500 . When AQI assume values of 101 or lower, air quality is considered unhealthy.

The Environmental Protection Agency (EPA) has assigned a specific color to each AQI category to make it easier to understand whether air pollution is about to reach unhealthy levels, as shown in Table 4.

Table4. Air Quality Index and Health Concern

\begin{tabular}{|l|l|l|}
\hline \multicolumn{1}{|c|}{ Air Quality } & AQI range & \multicolumn{1}{c|}{ Meaning } \\
\hline Good & 0 to 50 & $\begin{array}{l}\text { Air quality is considered satisfactory, and air pollution poses little or no } \\
\text { risk. }\end{array}$ \\
\hline Moderate & 51 to 100 & $\begin{array}{l}\text { Air quality is acceptable; however, for some pollutants there may be a } \\
\text { moderate health concern for a very small number of people who are } \\
\text { unusually sensitive to air pollution. }\end{array}$ \\
\hline $\begin{array}{l}\text { Unhealthy for } \\
\text { Sensitive Groups }\end{array}$ & 101 to 150 & $\begin{array}{l}\text { Members of sensitive groups may experience health effects. The general } \\
\text { public is not likely to be affected. }\end{array}$ \\
\hline Unhealthy & 151 to 200 & $\begin{array}{l}\text { Everyone may begin to experience health effects; members of sensitive } \\
\text { groups may experience more serious health effects. }\end{array}$ \\
\hline Very Unhealthy & 201 to 300 & Health alert: everyone may experience more serious health effects. \\
\hline Hazardous & 301 to 500 & $\begin{array}{l}\text { Health warnings of emergency conditions. The entire population is more } \\
\text { likely to be affected. }\end{array}$ \\
\hline
\end{tabular}

Source: EPA, 2012.

A fuzzy representation of the Air Quality is shown in Figure 5.

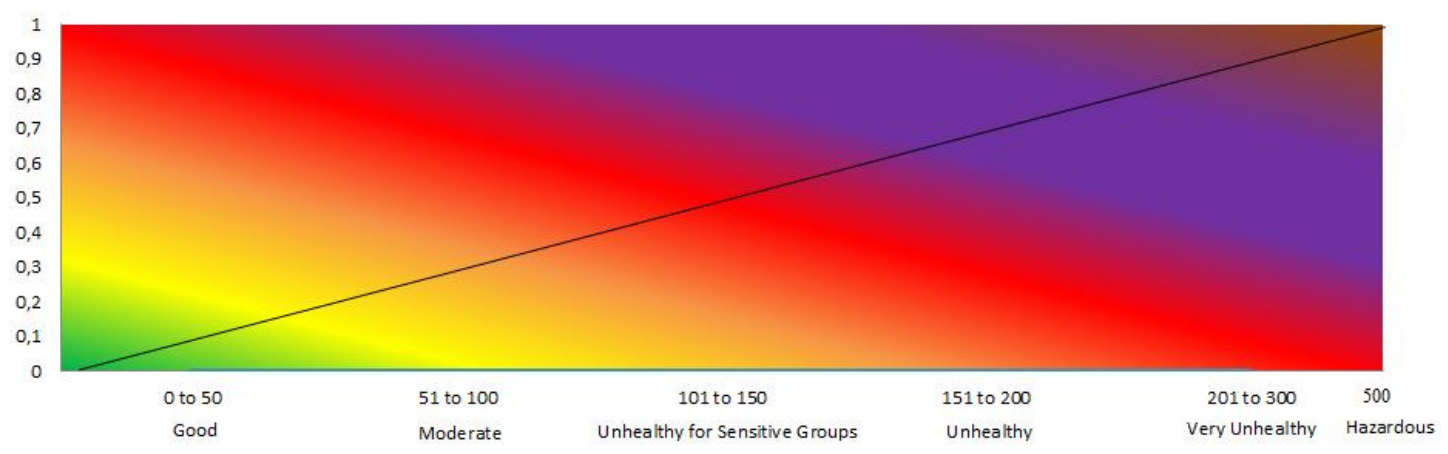

Figure5. Fuzzy representation of the air quality

Source: authors, 2018.

Authorities and people tend to be relatively more aware of airpollution. As David Briggs (2003) states: "Emissions to the atmosphere tend to be more closely modelled and measured, and more generally reported, than those other media, partly because of their greater importance for environmental pollution and heath".

In considering an industrial project location, the objective is to identify the areas affected by the dispersion and check for the existing pollution added to the new emissions. Eulerian, Lagrangian and Gaussian models have been tested. These models present considerable deviations from one another. When tested through simulation, the Gaussian model seemed to be the most adequate. As the focus is on the sources of pollutants, the main considerations relate to its polarizing power and, consequently, 
its emitting power, speed of winds, conservation in the atmosphere, and variations of air temperature. Turbulent flows are highly irregular, almost random and unpredictable details. Thus, turbulence is manifested irregularly, randomly as are fluctuations in velocity, temperature, and scalar concentrations around their principal values.

\section{Ground Contamination}

The contamination of soil comes mainly from industrial and agricultural residues, improper use; and inadequate agricultural techniques. It causes intoxication and allergies. Large quantities of dangerous wastes are generated by chemical manufacturing, pesticides, metals, textiles, petroleum refineries and other industries.

Heavy metals entail high toxicity in exceeded concentration and often cause irreversible damage to human health. An illustration of the acceptable limits for the presence of metals in soil is shown in Table 5 .

Table5. Environment quality standards for soil $(\mathrm{mg} / \mathrm{kg})$

\begin{tabular}{|c|c|c|c|c|c|c|}
\hline Heavy metal & Zn & As & Ni & Cr & Cu & Cd \\
\hline Evaluation Standard & 200 & 20 & 50 & 190 & 63 & 1 \\
\hline
\end{tabular}

Source: ZHICHAO; LIANGMIN; NING; XIAOXIAO, 2015.

The same authors present an environmental quality classification for contaminated soils, which is shown in Table 6.

Table6. Classification of soils contaminated with heavy metals

\begin{tabular}{|l|l|l|l|l|l|}
\hline $\begin{array}{c}\text { Heavy Metal } \\
\left(\text { mg.kg }^{-1}\right)\end{array}$ & $\begin{array}{c}\text { I } \\
\text { Excellent }\end{array}$ & $\begin{array}{c}\text { II } \\
\text { Clean }\end{array}$ & $\begin{array}{c}\text { III } \\
\text { Slightly Polluted }\end{array}$ & $\begin{array}{c}\text { IV } \\
\text { Moderately Polluted }\end{array}$ & $\begin{array}{c}\text { V } \\
\text { Heavily Polluted }\end{array}$ \\
\hline $\mathrm{Zn}$ & 100 & 200 & 250 & 300 & 500 \\
\hline $\mathrm{As}$ & 12 & 17 & 20 & 25 & 30 \\
\hline $\mathrm{Ni}$ & 40 & 50 & 65 & 80 & 200 \\
\hline $\mathrm{Cr}$ & 78 & 150 & 250 & 350 & 400 \\
\hline $\mathrm{Cu}$ & 35 & 50 & 100 & 150 & 400 \\
\hline $\mathrm{Cd}$ & 0.20 & 0.30 & 0.45 & 0.60 & 1.0 \\
\hline
\end{tabular}

Source: ZHICHAO; LIANGMIN; NING; XIAOXIAO, 2015.

The Canadian Soil Quality Classification is shown in Table 7.

Table7. Level of concern and ranges for soil quality

\begin{tabular}{|l|l|}
\hline \multicolumn{1}{|c|}{ Level of concern } & \\
\hline Very Low Ranges \\
\hline Low & $0-30$ \\
\hline Medium & $30-50$ \\
\hline High & $50-70$ \\
\hline Very high & $70-90$ \\
\hline
\end{tabular}

Source: Canada, 2007.

A fuzzy representation of the Soil Quality is shown in Figure 6.

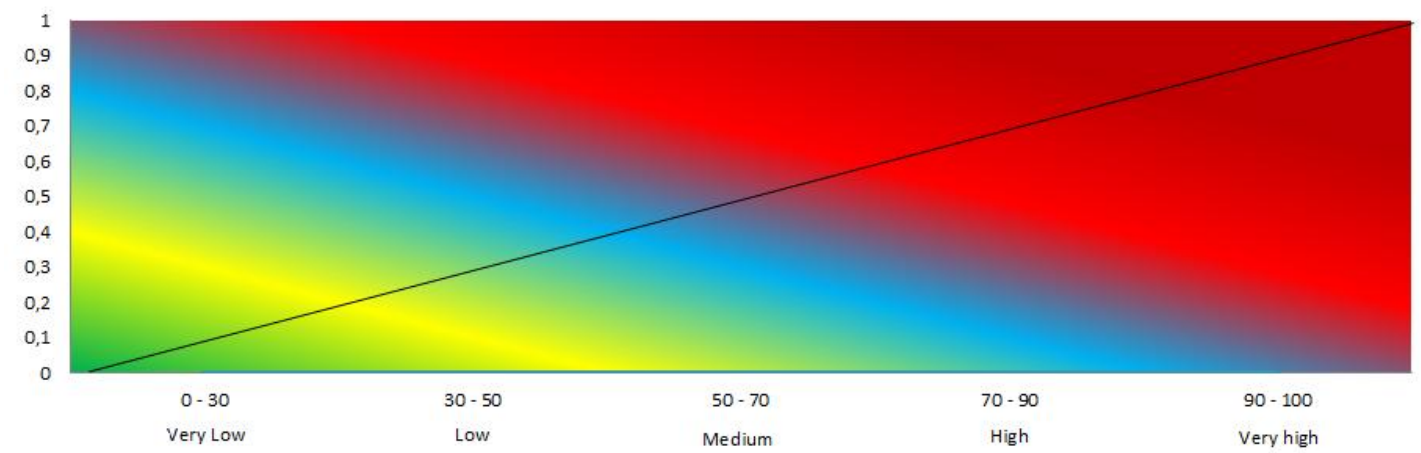

Figure6. Fuzzy representation of the soil quality

Source: authors, 2017 


\section{The Proposed ModeL}

The optimal distribution of activities in a given territory can be achieved through the confrontation of demand and supply of locational factors, imposing to this confrontation the critical limits recommended by WHO. In Figure 7 is shown an outline of the basic methodology.

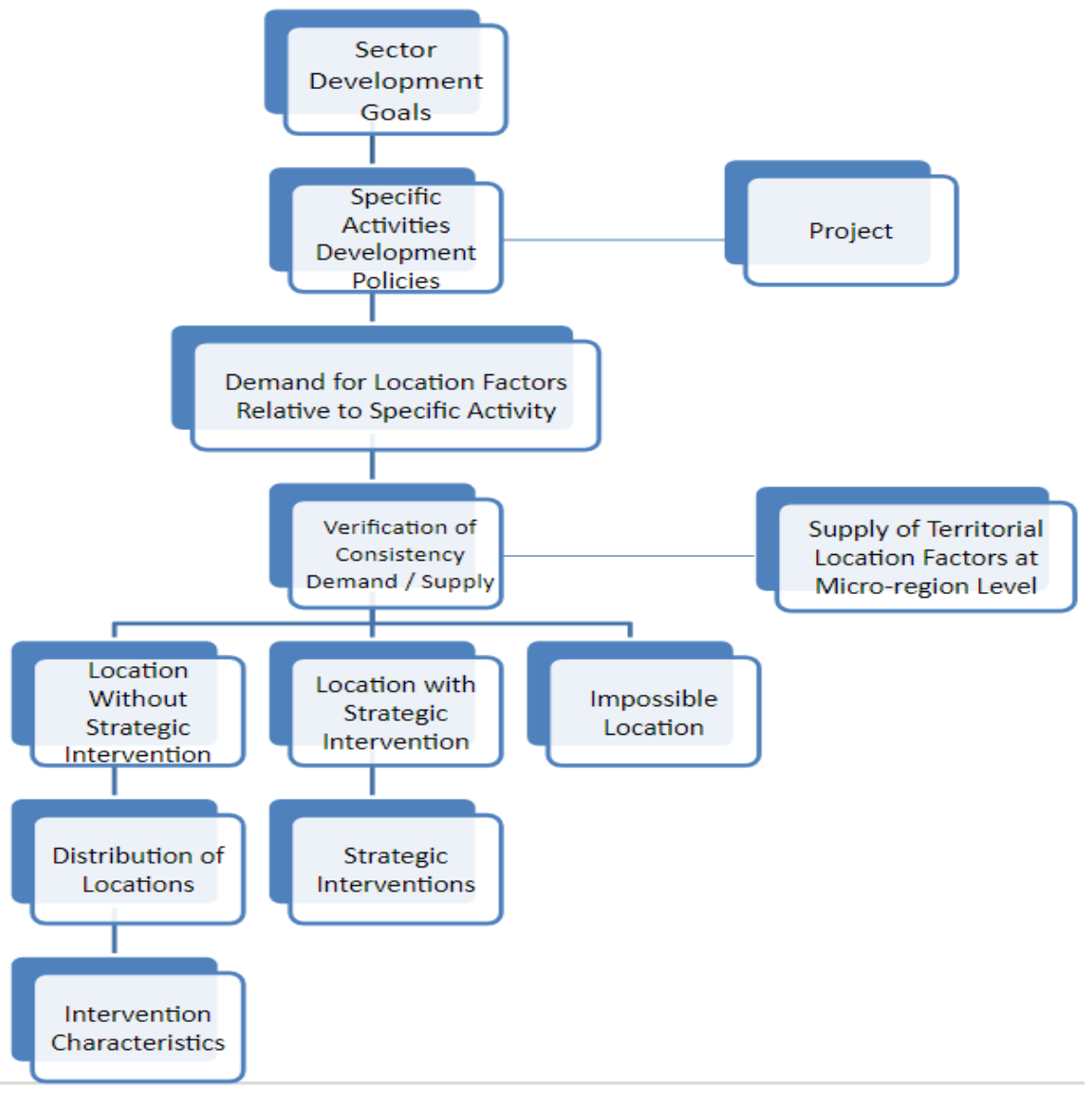

Figure7. Structure of the Methodology

Source: Authors

The COPPE/SOMEA/SEMA criteria imply that the planner's main objectives are:

- To optimize the employment of local resources;

- To increase employment rates;

- To avoid foreign direct investments in hazardous industries;

- To diversify the industrial sector for material sharing;

- To intensify symbiosis processes;

- To avoid saturations and boundary breaks.

The COPPE/SOMEA/SEMA methodology, first developed at the Martin Centre, in 1981, was redesigned in 2009 at the Department of Land Economy, Cambridge University, United Kingdom, UK, and was developed to provide planners, analysts and authorities with an instrument that allows managing options and priorities in planning industrial location, such as:

- Controlling of polarization phenomena to avoid saturation (including boundaries defined by WHO) ;

- Maximizing efficiency in the use of resources;

- Balancing industry with other local economic activities;

- Making compatible urban development with environmental equilibrium. 
The first step is to select areas that appear propitious for industrial development and then to determine the interventions that will facilitate and stimulate such development. For this purpose, the planner needs an instrument that allows evaluating local conditions in terms of environmental, economic and technical demands.

The second step is to define relatively homogenous micro areas or districts considering:

- The area of influence of the projects under analysis, the spatial distribution of the population and the wind predominance;

- The spatial distribution of industrial activities and the level of existent pollution;

- Orography analysis;

- Infrastructure analysis;

- Other alternatives of land use.

The selection of industries for a planned industrial area should be conditional based on the common use of infrastructure and also the sharing and reuse of resources.

\subsection{Factors Of Location, Infraestracture And Exchange Network}

The locational factors compose the supply and the demand matrices in which their respective importance is stated.

In Table 8, the most commonly considered factors of location of industrial projects are shown.

Table8. Locational factors commonly considered in industrial planning

\begin{tabular}{|c|c|}
\hline \# road transportation & Other Possibillities Of Integration Process \\
\hline \# rail transportation & \# activity in the agricultural section \\
\hline $\begin{array}{l}\text { \# hydrographic transportation } \\
+ \text { air transportation }\end{array}$ & $\begin{array}{l}\# \text { activity in the section process industry } \\
\# \text { activity in the financial section }\end{array}$ \\
\hline $\begin{array}{l}\text { \# market } \\
\text { \# Tax incentives / tax breaks } \\
\text { \# skilled labor } \\
\text { \# index of human development }\end{array}$ & $\begin{array}{l}\$ \text { activity in the in the market and repairs } \\
+ \text { activity in the section transports and communication } \\
+ \text { activity in the energy section, gas and water } \\
+ \text { activity in the section building }\end{array}$ \\
\hline Symbiossis Possibilities* & $\$$ \\
\hline $\begin{array}{l}\text { \# electric power } \\
\text { \# water availability to industrial use }\end{array}$ & $\begin{array}{l}\text { Distance Between Existing Pollution Levels And Who } \\
\text { Standards }\end{array}$ \\
\hline $\begin{array}{l}\text { \#atural gas } \\
\text { \# methane } \\
\text { \# waste } \\
\text { \# materials } \\
\text { \# information }\end{array}$ & $\begin{array}{ll} & \text { Pollution of water } \\
& \text { Pollution of air } \\
& \text { Pollution of soil }\end{array}$ \\
\hline \# industrial integration & \\
\hline \# industrial service & \\
\hline \& deployment service & \\
\hline $\begin{array}{l}\text { \# production service } \\
\text { \#aintenance service }\end{array}$ & \\
\hline $\begin{array}{l}\text { \# administrative labor } \\
\text { \# technical work }\end{array}$ & \\
\hline
\end{tabular}

*Symbiosis present special relevance because new parks tend to optimize infrastructure and common administrative work, and promote systematic reuse of materials and wastes (JACOBSEN, 2006).

Source: Authors, 2018.

A given factor usually presents different importance level to distinct projects. The fuzzy logic method differentiates them by degrees of membership and allows the analyst to consider:

- The WHO standards;

- The maximum allowable concentrations of various environment pollutants;

- The topographical and climatic characteristics of a given region; 
- The uses environmentally compatible with soil and aquifers

- Proximity of human settlements.

\subsection{The Mathematical Model}

The Space Organization is part of the Environmental Science. The transformation of complex industrial parks in eco-industrial parks is a challenge for engineering and economics of the environment.

The organization of the economic space implies identifying the distance between the requirements of the demand profiles and the level of attendance to those requirements inagiven space domain. The possibility of symbiosis is also measured as the distance between memberships.

Let $\mathbf{A}$ be a set of projects whose demand profiles are known and $\mathbf{B}$, a set of spatial units whose potentialities are also known. Pollution is considered as a critical factor, a limiting factor for industrial location.

The distance between elements $\mathbf{i}$ of set $\mathbf{A}$ and $\mathbf{k}$ of set $\mathbf{B}$ is defined by the matrix of membership relations, as follows:

Let $\mathbf{F}=\{\mathbf{f i} \mid \mathbf{1}, \ldots, \mathbf{n}\}$ a finite set of general location factors denoted generically by $\mathbf{f}$.

Let $\mathbf{A}=\left(\mathbf{a}_{\mathbf{i j}}\right)_{\mathbf{h} \times \mathbf{n}}$ represent the industrial demand of $\mathbf{h}$ types of industries for $\mathbf{n}$ location factors with environmental 0000restrictions. Then let $\mathbf{B}=\left(\mathrm{b}_{\mathrm{jk}}\right)_{\mathrm{n} \times \mathrm{m}}$ hold for the supply of those factors by $\mathbf{m}$ locational alternatives, including levels of environmental saturation.

Therefore, $\breve{\boldsymbol{A}}$, definedin $\mathbf{f}$, is a fuzzy set of ordered pairs as follows:

$$
\check{\boldsymbol{A}}=\left\{\left(\boldsymbol{f}, \boldsymbol{\mu}_{\breve{A}}(\boldsymbol{f}) \mid \boldsymbol{f} \epsilon \boldsymbol{F}\right)\right\}
$$

Where $\check{A}$ is a fuzzy representation of the demand matrix $\mathbf{A}$, and $\boldsymbol{\mu}_{\breve{A}}(\boldsymbol{f})$ represents the degree of importance of factors that may be:

Similarly,

$$
\breve{B}=\left\{\left(\boldsymbol{f}, \boldsymbol{\mu}_{\breve{B}}(\boldsymbol{f}) \mid \boldsymbol{f} \epsilon \boldsymbol{F}\right)\right\}
$$

Where $\breve{\boldsymbol{B}}$ is a fuzzy representation of the supply matrix $\mathbf{B}$, and $\boldsymbol{\mu}_{\breve{\boldsymbol{B}}}(\boldsymbol{f})$ represents the degree of availability of factors at locational alternatives:

\section{Superior - Good - Regular - Weak}

Or environmental condition:

\section{Great - Good - Regular - Poor}

\subsection{Matrix Operations (Basic Model)}

Let $\mathbf{C}=\mathbf{A} \otimes \mathbf{B}=\left(\mathbf{c}_{\mathbf{i k}}\right)_{\mathbf{m} \times \mathbf{z}}$ be the matrix of location possibilities for project $\mathbf{i}$ in planning area $\mathbf{k}$, such that $\boldsymbol{m a x}_{\boldsymbol{k}}\left\{\boldsymbol{c}_{\boldsymbol{i k}}\right\}=\overline{\boldsymbol{c}_{\boldsymbol{i}}}$ shows the best location for project $\mathbf{i}$ and $\boldsymbol{m a x}_{\boldsymbol{i}}\left\{\boldsymbol{c}_{\boldsymbol{i} \boldsymbol{k}}\right\}=\overline{\boldsymbol{c}_{\boldsymbol{k}}}$ give the best project type for the site $\mathbf{k}$. And let $\mathbf{c}_{\mathbf{i k j}}$ represent the evaluation of location $\mathbf{k}$ in light of factor $\mathbf{j}$ according to the demand of project $\mathbf{i}$.

Initially, the values of matrices $\mathbf{A}$ and $\mathbf{B}$ are chosen as linguistic variables, as illustrated in Table 9.

Table9. Linguistic values for factors' supply and demand

\begin{tabular}{|c|c|c|c|c|c|}
\hline Factors & \multicolumn{3}{|c|}{ Sites' supply } & \multicolumn{2}{c|}{ Projects' demand } \\
\hline & $\mathrm{B}_{1}$ & $\mathrm{~B}_{2}$ & $\mathrm{~B}_{3}$ & $\mathrm{~A}_{1}$ & $\mathrm{~A}_{2}$ \\
\hline $\mathbf{f}_{\mathbf{1}}$ & $\{0\}$ & $\varnothing$ & Superior & Conditioning & Critical \\
\hline $\mathbf{f}_{\mathbf{2}}$ & $\varnothing$ & Superior & Good & Critical & Conditioning \\
\hline $\mathbf{f}_{\mathbf{3}}$ & Good & Superior & Good & Critical & Critical \\
\hline $\mathbf{f}_{\mathbf{4}}$ & $\{0\}$ & Superior & Good & Little Conditioning & Irrelevant \\
\hline $\mathbf{f}_{\mathbf{5}}$ & Regular & $\{0\}$ & $\varnothing$ & Irrelevant & Conditioning \\
\hline $\mathbf{f}_{\mathbf{6}}$ & Superior & Superior & Superior & Conditioning & Irrelevant \\
\hline $\mathbf{f}_{7}$ & Good & Good & Good & Critical & Little Conditioning \\
\hline
\end{tabular}

Source: Based on NARASIMHAN (1979) and on COPPE-Cosenza Model 
Where $\mathbf{B}_{\mathbf{1}}, \mathbf{B}_{\mathbf{2}}$ and $\mathbf{B}_{\mathbf{3}}$ are spatial units such as elementary areas, industrial districts or eco-industrial parks. As indicated before, $\boldsymbol{\mu}\left(\mathbf{a}_{\mathrm{ij}}\right)$ may also represent a given level of pollution and $\boldsymbol{\mu}\left(\mathbf{b}_{\mathbf{j k}}\right)$, a level of acceptability. For example, if in Table $9, \mathbf{f}_{7}$ represents the pollution increment of a new project, $\mathbf{B}_{\mathbf{1}}, \mathbf{B}_{2}$ and $\mathbf{B}_{\mathbf{3}}$ would be good location alternatives.

Table 10 shows a set of confrontation results of requirement levels $\left(\mathbf{a}_{\mathbf{i j}}\right)$ with the attendance capacities $\left(\mathbf{b}_{\mathbf{j k}}\right)$.

Table10. Confrontation of demand and supply levels

\begin{tabular}{|c|c|c|c|c|}
\hline $\mathbf{a}_{\mathbf{i j}}(\bullet) \mathbf{b}_{\mathbf{j} \mathbf{k}}$ & $\mathbf{A}^{\prime}$ & $\mathbf{B}$ & $\mathbf{C}^{\prime}$ & 0 \\
\hline $\mathbf{A}$ & 1 & 0 & 0 & 0 \\
\hline $\mathbf{B}$ & $1+\frac{1}{n}$ & 1 & 1 & 0 \\
\hline $\mathbf{C}$ & $1+\frac{2}{n}$ & $1+\frac{1}{n}$ & \\
\hline $\mathbf{D}$ & $1+\frac{3}{n}$ & $1+\frac{2}{n}$ & $1+\frac{1}{n}$ & 1 \\
\hline
\end{tabular}

Source: Authors

Where $\mathbf{n}$ is the number of factors, including pollution indexes as critical factors; $\mathbf{A}, \mathbf{B}, \mathbf{C}$ and $\mathbf{D}$ designate levels of demand and A', B', C' and 'D', levels of supply. The criteria showed in Table 10 was applied by Petrobras in the Biodiesel Plants Location Program, processing about 140 thousand variables.

Another possible set of results for the confrontation of demand levels with supply levels was presented in a lecture series at St. Antony's College, Oxford, in 2005, and is shown in Table 11.

Table11. Alternative confrontation of demand and supply levels

\begin{tabular}{|c|c|c|c|c|}
\hline $\mathbf{a}_{\mathbf{j i}}(\bullet) \mathbf{b}_{\mathbf{j k}}$ & $\mathbf{A}^{\prime}$ & $\mathbf{B}^{\prime}$ & $\mathbf{C}^{\prime}$ & $\mathbf{D}^{\prime}$ \\
\hline $\mathbf{A}$ & 1 & 0 & 0 & 0 \\
\hline $\mathbf{B}$ & $1+\frac{1}{3^{\mathrm{n}}}$ & 1 & 0 & 0 \\
\hline $\mathbf{C}$ & $1+\frac{2}{2^{\mathrm{n}}}$ & $1+\frac{1}{3^{\mathrm{n}}}$ & 1 & 1 \\
\hline $\mathbf{D}$ & $\left(1+\frac{1}{1^{\mathrm{n}}}\right)$ & $1+\frac{2}{2^{\mathrm{n}}}$ & $1+\frac{1}{3^{\mathrm{n}}}$ & \\
\hline
\end{tabular}

Source: Authors.

It is possible to replace the criteria presented previously by a diffuse hierarchical scheme that includes different types of pollution, either as a "demand" of each industrial project or as a level of support capacity of each site considered. As before $\mathbf{A}=\left(\mathbf{a}_{\mathbf{i j}}\right)_{\mathbf{h} \times \mathbf{n}}$ denotes comparative results between demand and supply of each factor, as shown in Table 12 .

Table12. Fuzzy comparison between demand and supply of factors

\begin{tabular}{|c|c|c|c|c|c|}
\hline \multicolumn{6}{|c|}{ Matrix $\widetilde{C}_{\mathrm{ik}}$} \\
\hline Demand for factors $(\widetilde{A})$ & \multicolumn{5}{|c|}{ Supply of factors $(\widetilde{B})$} \\
\hline $\mathrm{a}_{\mathrm{ij}}(\bullet) \mathrm{b}_{\mathrm{jk}}$ & 0 & \multicolumn{3}{|c|}{$\mu_{\tilde{B} \mathrm{i}}(\mathrm{x})$} & 1 \\
\hline 0 & $0^{+}$ & . & . & . & $0^{++}$ \\
\hline . & & 1 & & & $1+\left[\mu_{\tilde{B}}(X)-\mu_{\tilde{A}}(X)\right]$ \\
\hline$\mu_{\tilde{A}_{i}}(X)$ & & & 1 & & \\
\hline . & $1+\left[\mu_{\tilde{B}}(X)-\mu_{\tilde{A}}(X)\right]$ & & & 1 & \\
\hline 1 & 0 & . & . & . & 1 \\
\hline
\end{tabular}

Source: Authors.

Where: $\boldsymbol{\mu}_{\tilde{\mathbf{A}}}(\mathbf{x})=$ degree of importance of the factor to project $\mathbf{i}$

$\boldsymbol{\mu}_{\widetilde{\boldsymbol{B}}}(\mathbf{x})=$ degree of supply of the factor by the space unit $\mathbf{k}$

Clearly, in Table 12, the restrictions situated below the main diagonal, where the demand overweighs the supply. 


\subsection{Specific Factors - Crisp Operations}

Let $\widetilde{\boldsymbol{A}}^{*}=\left(\widetilde{\boldsymbol{a}_{i j}}\right)_{\mathbf{m} \times \mathbf{n}^{\prime}}$ be the industrial demand matrix of $\mathbf{m}$ kinds of industries for $\mathbf{n}$ ' specific location factors. For the present purposes, matrix $\widetilde{\boldsymbol{A}}^{*}$ includes pollutants emissions, which demand level is always considered critical. Let $\widetilde{A}^{*}=\left\{\boldsymbol{f}, \boldsymbol{\mu}_{\widetilde{A}}^{*}(\boldsymbol{f}) \mid \boldsymbol{f} \in \boldsymbol{F}\right\}$ be a fuzzy representation of the matrix $\mathrm{A}^{*}$.

Let $\overline{\mathrm{B}}^{*}=\left(\overline{\mathrm{b}}^{*}{ }_{\mathrm{ij}}\right)_{\mathrm{n}^{\prime} \times \mathrm{m}}$ be the matrix of the territorial supply of the same $\mathbf{n}$ ' specific location factors, and let $\widetilde{B}^{*}=\left\{f, \mu_{\tilde{B}}^{*}(f) \mid f \in F\right\}$ be its fuzzy representation.

Then, one can define matrix $\widetilde{\boldsymbol{C}}^{*}=\widetilde{\boldsymbol{A}}^{*} \otimes \widetilde{\boldsymbol{B}}^{*}=\left[\widetilde{\mathbf{c}}_{\mathbf{i k}}{ }_{\mathbf{h} \times \mathbf{m}}\right.$, where $\widetilde{\mathbf{c}}^{*}{ }_{\mathbf{i k}}$ is a fuzzy coefficient.

Now, let $\boldsymbol{\Gamma}=\left[\mathbf{Y}_{\mathbf{i k}}\right]_{\mathbf{m x q}}=\mathbf{C} \otimes \mathbf{C}^{*}$ be the final coefficient. This operation follows the rules showed in Table 13.

Table13. Rules for final locational coefficients

\begin{tabular}{|c|c|c|}
\hline \multicolumn{3}{|c|}{$\gamma_{i k}$} \\
\hline${ }^{2}$ & $>0$ & $\varnothing$ \\
\hline $\mathbf{C}_{\mathrm{ik}}^{*}$ & & \\
\hline 0 & 0 & 0 \\
\hline$\nexists$ & 0 & 0 \\
\hline$>0$ & $\mathrm{C}_{\mathrm{ik}}+\mathrm{C}_{\mathrm{ik}}^{*}$ & $\mathrm{C}_{\mathrm{ik}}^{*}$ \\
\hline
\end{tabular}

Source: Authors

In applying the rules shown in Table 13, the planner must impose the WHO's limits in such a way that, in case any limit is reached or surpassed, $\boldsymbol{C}_{\boldsymbol{i k}}^{*}$ must equal zero and the location $\mathbf{k}$ is rejected as a possible location for project $\mathbf{i}$.

From the territorial units' point of view, the distances between the pollution "demand" by the industry and their ability to respond to it may indicate the need for public authorities' action. In Cubatão, for example, air pollution levels must be reduced to a large extent before any new industrial project that "requires" emissions into the atmosphere can be located there.

\subsection{Delta Operator}

LetE $=\left(\boldsymbol{\varepsilon}_{\boldsymbol{i l}}\right)_{\boldsymbol{h} \boldsymbol{h}}$ be a diagonal matrix such as

$$
\varepsilon_{u l}= \begin{cases}0, & \text { if } \mathrm{i} \neq 1 \\ \frac{1}{\sum_{j=1}^{\mathrm{a}_{2}} \mathrm{a}_{i j}}, & \text { if } \mathrm{i}=1\end{cases}
$$

We still define $\Delta=\left[\boldsymbol{\epsilon} \boldsymbol{x} \sum_{j=\mathbf{1}}^{n_{\Sigma}} \boldsymbol{b}_{\boldsymbol{j}}\right]$ as the matrix representing the possible location of $\mathbf{h}$ kinds of industries in $\mathbf{m}$ alternatives, with each element $\boldsymbol{\delta}_{\boldsymbol{i} \boldsymbol{k}}$ of the matrix $\Delta$ representing locations, ordering the regions by projects.

- $\delta_{\mathrm{ik}}=1$ if area $\mathbf{k}$ attends the demand at the required level.

- $\delta_{\mathrm{ik}}<1$ means that at least one demanded factor was not provided.

- $\delta_{\mathrm{ik}}>1$ if area $\mathbf{k}$ supplies more conditions than the demanded ones.

The matrix of systematic confrontation between the project profile (demand for general and specific factors) versus locational resources (supply factors) and pollution levels and indicesareable to indicate the best decision, as shown in Table 14 .

Table14. Decision Criteria

\begin{tabular}{|c|c|c|c|c|c|}
\hline Demand for factors $(\widetilde{\boldsymbol{A}})$ & \multicolumn{5}{|c|}{ Supply of factors $(\widetilde{\boldsymbol{B}})$} \\
\hline $\mathrm{a}_{\mathrm{ij}}(\boldsymbol{\bullet}) \mathrm{b}_{\mathrm{jk}}$ & 0 & \multicolumn{3}{|c|}{$\mu_{\tilde{B} \mathrm{i}}(\mathrm{x})$} & 1 \\
\hline 0 & $0^{+}$ &. &. &. & $0^{++}$ \\
\hline. & & 1 & & & $1+\left[\mu_{\tilde{B}}(X)-\mu_{\tilde{A}}(X)\right]$ \\
\hline$\mu_{\tilde{A}_{i}}(X)$ & $\delta_{\mathrm{ik}}<1$ & & 1 & & $\delta_{\mathrm{ik}}>1$ \\
\hline$\cdot$ & $1+\left[\mu_{\tilde{B}}(X)-\mu_{\tilde{A}}(X)\right]$ & & & 1 & \\
\hline 1 & 0 &. &. &. & 1 \\
\hline
\end{tabular}

Source: Authors 
To attend WHO's standards $\delta_{\mathrm{ik}} \geq 1$. However, an essential question still remains: how to measure the pollution that will be emitted by a new industrial plant?

\subsection{Production Functions}

According to Rocha et al. (2013), "Grossman and Krueger adapted the Kuznets work using a crosssection model for 42 countries, correlating air quality with level of economic growth, the authors concluded that the concentration of pollutants increases with GDP per capita". A typical Kuznets Curve is shown in Figure 8.

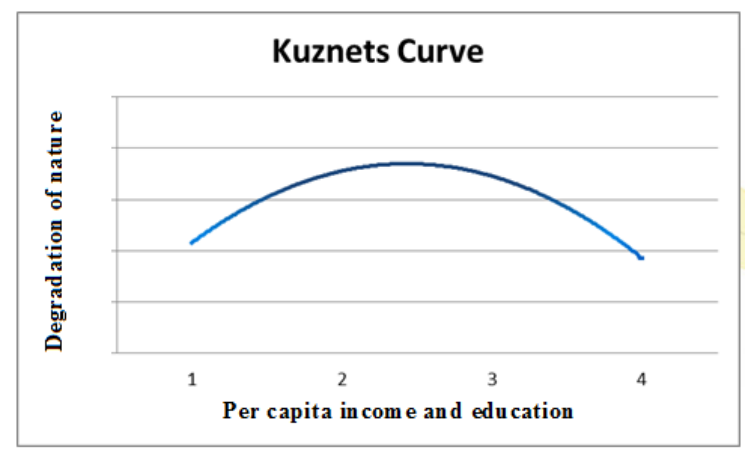

Figure8. Kuznets Curve

Source: SELDEN; DAQING (1994)

The analysis through production function considers scale and technology. At the project level and in a limited set of locations it is possible to expand the number of considered variables, such as scale factors, technologies, quantities and types of inputs and their technical relationships, accessibility and support activities.

Obviously, the relationship between the increases in GDP and the quality of life found at the national level does not apply at the local level. In particular, the growing constraints of congested space give rise to diseconomies of scale and diminishing returns.

In order to choose the optimal acceptable location for a given project, it is necessary to take into account not only the new emissions, obtainable from its expanded production function, but also the dispersion patterns of the pollutants among the planning areas. For this purpose, knowledge about the expanded production functions of industrial activities is the basis for simulation of pollution increase because it allows it to anticipate the pollutants charge associated with the considered projects.

\section{Final Considerations}

The environmental disasters observed around the World, as occurred in Cubatão, have two main causes: 1) In practice, decision makers cannot count on adequate information on the consequences of their decisions, or lack of decisions, relative to industrial localization, and 2) In such a situation, authorities feel comfortable and do not demand the information that should be the basis of adequate decisions. The result could not be worse. The overconcentration of highly polluting industrial plants, not meeting minimum environmental standards, has been highlighted by the media. Unfortunately, at the moment of bad news, serious damage has already occurred and high social costs have become inevitable.

The World Bank proposal could be feasible and bring benefits to all parties if the World Bank, rather than simply financing the migration of industries to the least developed countries, acted in a similar way to the International Monetary Fund (IMF). Just as the IMF requires borrowing governments to adopt the measures deemed necessary for financial rebalancing, the World Bank should demand compliance with the standards set by the WHO with regard to preserving the quality of the environment.

This paper proposes a fuzzy model capable of avoiding the localization of any industrial project that implies overweight of WHO standards. The proposed model is designed to prevent environmental degradation and diseases by considering the level of pollution already achieved in a particular planning area, the increase brought about by a given industrial project and the safety limits established by the WHO. The proposed model also produces information about a given industrial project and a particular planning area, indicating if public policies and public actions are needed. In addition, the proposed model allows simulating different scenarios, changing the set of industrial projects, 
including sectors, scales and technologies; changing the supply profiles of the planning areas; and adopting health and environmental standards that are stricter than those of WHO.

However, it is clear the proper operationalization of the proposed model requires the implementation of a culture of planning, with organized and cumulative provision of the necessary information and with the gradual change of patterns of behavior that are often already ingrained.

In summary, the available scientific knowledge on the Environment and Human Health is enough to avoid disasters, as it happened in Cubatão and in several other cities of the world. However, to achieve this, a planning effort is required, involving adequate data provision, specialized professionals and, above all, political disposition. This paper presents an instrument capable of balancing the negative and positive effects of industrial location in advance and, in this way, avoiding socially disadvantageous decisions.

\section{REFERENCES}

[1] BBC. (2016). Polluted air affects 92\% of global population, says WHO. BBC News. Available at: https://www.bbc.com/news/health-37483616. Access: July 11, 2018.

[2] Briggs, D. (2003). Impact of environmental pollution on health: balancing risk. British Medical Bulletin, Vol. 68.

[3] Brown, R.M.; Mcclelland, N.I.; Deininger, R.A.; Tozer, R.G. (1970). Water quality index - do we dare?Water Sewage Works, 117(10). 339-343. 1970.

[4] Canada. (2007). Canadian Soil Quality Guidelines for the Protection of Environmental and Human Health, Canadian Council of Ministers of the Environment. Available at: http://ceqg-rcqe.ccme.ca/ download/en/342/. Access: June 12, 2018.

[5] Cosselman, K. E.; Navas-Acien, A.; Kaufman, J.D. (2015).Environmental factors in cardiovascular disease. Nature Reviews Cardiology, 12, 627-642. Available at: https://www.nature.com/articles/ nrcardio.2015.152. Access: Mar 12, 2018.

[6] Crawford-Brown, D.; Crawford-Brown, S. (2012). Cumulative Risk Assessment Framework for Waterborne, Journal of Environmental Projection, 2012, 3, 400-413. Available at: https://file.scirp.org/ pdf/JEP2012 0500005_19306539.pdf. Access: July 15, 2018.

[7] EPA, Air Quality Index. (2012). Review of Air Quality Index and Air Quality Index. Available at: https://airnow.gov/index.cfm?action=aqi. Access: July 7, 2017.

[8] Hickman, L. (2012). Doha climate talks: should rich countries shoulder "responsibility". The Guardian.

[9] Jacobsen, N. B. (2006). Industrial Symbiosis in Kalundborg, Denmark: A Quantitative Assessment of Economic and Environmental Aspects.Journal of Industrial Ecology, Volume10, Issue1-2, Pages 239-255. Available at: https://onlinelibrary.wiley.com/doi/abs/10.1162/108819806775545411. Access: July 19, 2018.

[10] Miranda, G. (2012). Exportação de Poluição de países ricos movimenta conferência do clima. Folha de São Paulo.

[11] Narasimhan, R. (1979). A Fuzzy Subset Characterization Of A Site-Selection Problem. Decision Sciences, Volume10, Issue4, October 1979. Pages 618-628. Available at: https://onlinelibrary.wiley.com/doi/pdf/ 10.1111/j.1540-5915.1979.tb00051.x. Access: Jan 15, 2018.

[12] Nathason, J. A.; Schneider, R. A. (2016). Basic environmental technology: water supply, waste management, and pollution control. 6th Ed. London: Pearson, 2016.

[13] Nobre, R.C.M.; Rotunno Filho, O. C; Mansur, W.J; Nobre, M.M.M; Cosenza, C.A.N. Groundwater vulnerability and risk mapping using GIS, modelling and fuzzy logic tool. Journal of Contaminant Hydrology, 94, 277-292. Access: May 20, 2018.

[14] Pedroso, D. (2016, May 14). Santos e Cubatão têm índices de Poluição acima do recomendado pela OMS (WHO). A Tribuna. Available at: http://.atribuna.com.br./noticias. Access: July 10, 2018.

[15] Poincaré, H. (1995). O valor da ciência. Rio de Janeiro: Contraponto.

[16] Ramaraju, A.V.; Veni, K. K. (2017). Groundwater vulnerability Assessment by

[17] DRASTIC method using GIS. International Journal of Geo informatics and Geological Science, Vol 4, (2). Access: July 12, 2018.

[18] Rocha, L. A.; Khan, A. S.; Lima, P.V. P. S. (2013). Nível Tecnológico e emissão de poluentes: uma análise empírica a partir da curva de Kuznets ambiental. Economia Aplicada, v. 17, n. 1, 2013, pp. 21-47. Access: Jan 12, 2018.

[19] Selden, T.; Daqing, S. (1994). Environmental Quality and Development: Is There a Kuznets Curve for Air Pollution Emissions?Journal of Environmental Economics and Management, vol. 27, issue 2, 147-162. 
[20] SOARES. J. (2016, Dez 21). 10 Poluentes que mais matam no mundo. Revista Superinteressante. Available at: https://super.abril.com.br/blog/superlistas/10-poluentes-que-mais-matam-no-mundo/. Access: July 13, 2018.

[21] Stempvoort, D. V.; Ewert, L.; Wassenaar, L. (1993). Aquifer Vulnerability Index (AVI): a GIS compatible method for groundwater vulnerability mapping. Canadian Water Resources Journal 18(1):25-37, 1993.

[22] World Bank (1991, Dez 12). Memo by Lawrence Summers. Available at: http://www.whirledbank.org/ ourwords/summers.html. Access: July 10, 2018.

[23] World Health Organization. (2015, Jan 19) Noncommunicable diseases prematurely take 16 million lives annually. Available at:http://www.who.int/mediacentre/news/releases/2015/noncommunicable-diseases/ en/. Access: July 9, 2018.

[24] Zhichao, L; Liangmin, G; Ning, L.; Xiaoxiao, Z. (2015, Mar). A Comparative Analysis of Environmental Quality Assessment Methods-a Case Study of Heavy Metal-Contaminated Soil. Proceedings of the 2015 International Conference on Materials, Environmental and Biological Engineering. Available at: https://www.atlantis-press.com/proceedings/mebe-15/17851. Access: July 15, 2018.

Citation: Carlos A. N. Cosenza, et.al. "Planning Industrial Location: A Fuzzy Model for Preventing Disastrous Overconcentration of Industries" International Journal of Managerial Studies and Research (IJMSR), vol 7, no. 3, 2019, pp. 38-54. doi: http://dx.doi.org/10.20431/2349-0349.0703005.

Copyright: (C) 2019 Authors. This is an open-access article distributed under the terms of the Creative Commons Attribution License, which permits unrestricted use, distribution, and reproduction in any medium, provided the original author and source are credited. 